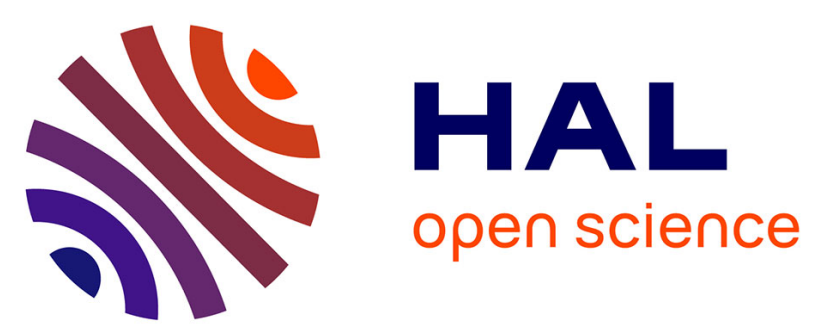

\title{
Numerical simulation of the abrasive waterjet (awj) machining: multi-fluid solver validation and material removal model presentation
}

Mohammadi Zaki, Christophe Eric Corre, Patrick Kuszla, Francisco Chinesta

\section{- To cite this version:}

Mohammadi Zaki, Christophe Eric Corre, Patrick Kuszla, Francisco Chinesta. Numerical simulation of the abrasive waterjet (awj) machining: multi-fluid solver validation and material removal model presentation. International Journal of Material Forming, 2008, 1 (S1), pp.1403-1406. 10.1007/s12289008-0127-8 . hal-01742694

\section{HAL Id: hal-01742694 \\ https://hal.science/hal-01742694}

Submitted on 26 Mar 2018

HAL is a multi-disciplinary open access archive for the deposit and dissemination of scientific research documents, whether they are published or not. The documents may come from teaching and research institutions in France or abroad, or from public or private research centers.
L'archive ouverte pluridisciplinaire HAL, est destinée au dépôt et à la diffusion de documents scientifiques de niveau recherche, publiés ou non, émanant des établissements d'enseignement et de recherche français ou étrangers, des laboratoires publics ou privés. 


\title{
Numerical Simulation of the Abrasive WaterJet (AWJ) Machining: Multi-Fluid Solver Validation and Material Removal Model Presentation
}

\author{
M. Zaki ${ }^{1}$, C. Corre ${ }^{2}$, P. Kuszla ${ }^{1}$, F. Chinesta ${ }^{3}$
}

\author{
${ }^{1}$ SINUMEF, ENSAM, 151 Bd de l'Hôpital 75013 Paris - France \\ URL: sin-web.paris.ensam.fr e-mail:mazen.zaki@paris.ensam.fr; patrick.kuszla@ paris.ensam.fr \\ ${ }^{2}$ LEGI, UMR 5519, BP 53, 38041 Grenoble - France \\ URL: www.legi.ingg.fr e-mail: christophe.corre@hmg.inpg.fr \\ ${ }^{3}$ LMSP, ENSAM, 151 Bd de l'Hôpital 75013 Paris - France \\ URL: www.paris.ensam.fr/lmsp e-mail: francisco.chinesta@paris.ensam.fr
}

\begin{abstract}
The increasing use of high-pressure water jets in the industry for machining materials yields numerous studies aiming at the optimization of this technology. Since the experimental study of pure or abrasive water jet cutting is complex to carry out, the numerical simulation of this process stands as an attractive alternative. Such a simulation relies on the coupling of numerical tools devoted on one hand to the description of the high-velocity jet and on the other hand to the deformation of the impacted material. The present paper provides a careful validation for the simulation of an impinging abrasive liquid jet, taking progressively into account the necessary features: impingement, free-surface, particles.
\end{abstract}

KEYWORDS: Fluid-Structure Interaction, Abrasive WaterJet, Numerical Simulation

\section{INTRODUCTION}

The present work is devoted to the numerical simulation of the cutting and drilling mechanisms for Abrasive Water Jet with a strong emphasis on the simulation of the jet properties; a fluid-structure interaction simulation using a simple model of material removal is also presented.

\section{VALIDATION PROCEDURE}

In order to perform a numerical simulation of the process of AWJ machining, a Computational Fluid Dynamics (CFD) solver, which simulates the dynamics of the abrasive jet, must be coupled with a material erosion model. In the present study, the commercial CFD solver Fluent 6 is used in parallel with an inhouse erosion and material removal application.

An AWJ is described as a multiphasic flow with two fluid phases (water and air) and one dispersed solid phase, made of the abrasive particles. The jet is pumped out at a great velocity and impinges on the target workpiece. The impact of the fluid and the particles generates a high pressure level which leads to the material erosion.
According to our bibliographical research, there are no previous numerical simulations of the whole material removal process; one of the difficulties lies in the need for a dynamic meshing of the fluid domain to take into account the material removal. However, before proceeding to this final fluid-structure step, it seems crucial to perform a careful validation of the CFD solver, incorporating progressively the numerical ingredients needed to correctly represent a liquid jet including particles, that flows through still air and impacts a rigid plate: these key ingredients are the volume of fluid approach to account for multiphase flows and the discrete phase transport model.

\subsection{Simulation of a single phase impinging jet}

The main parameters of this first configuration are the jet Reynolds number and the ratio between the distance $H$ separating the nozzle from the impacted surface and the interior diameter $D$ of the nozzle. The case retained in the present work is the impinging jet studied by Souris et al. in [6], following the experimental work of Knowles and Myszko [4]; the flow liquid is water which is pumped out from a circular nozzle with an internal diameter of $D=12.7 \mathrm{~mm}$, 
$H / D=10$ and a Reynolds number equal to 90000 . The computational grid is made of 18360 cells and is refined in the zones containing the jet and the impact region. Our simulation results are in very good agreement with the experiments of Knowles and Myszko as well as with the numerical and analytical models studied by Souris et al, as can be observed in Fig. 1 where a comparison of the non-dimensional velocity profiles in the free jet (development) region is displayed. Once the jet has impacted the wall, its flow direction is changed with the liquid flowing along the wall surface. The curves presented in Fig. 2 demonstrate the good agreement between the present numerical simulations and the reference works in this walljet region.

\subsection{Simulation of the water jump}

When a vertical (or obliquely inclined) liquid jet flowing through still air impinges a horizontal surface and spreads in the radial direction, a hydraulic jump may appear [7]. The numerical simulation of such phenomenon is a challenging task since it involves in particular a strongly distorted free surface (as well as a recirculating flow) $[2,3]$. Thus, reproducing this flow feature seems a significant test to properly validate the multiphase model (VOF) in use for liquid jet impact in the context of AWJ machining.

A typical hydraulic jump is presented in Fig. 3 taken from Kate et al. [7]. The flow field can be divided into three main regions: the free jet region, the impingement region and the wall jet region, these latter being themselves successively decomposed into the region of boundary-layer-type flow and of fully developed flow, the region immediately before the hydraulic jump, the region of the hydraulic jump, and the region downstream of the jump.

Numerical simulations were carried out for a 2D axisymmetric unsteady configuration with the VOF multiphase model and a standard $k-\epsilon$ turbulence model. The nozzle diameter is equal to $10 \mathrm{~mm}$ and the impact occurs at $h / D=10$. The simulations were all run for a time long enough to reach a steady state: the time steps used for computing the flow evolution are respectively $6.10^{-5} \mathrm{~s}, 3.10^{-5} \mathrm{~s}, 1.10^{-5} \mathrm{~s}$ and $1.10^{-5} s$ for the four considered configurations which correspond to a water flow rate $Q$ successively equal to $5.10^{-5}, 10.10^{-5}, 20.10^{-5}$ and $25.10^{-5} \mathrm{~m}^{3} / \mathrm{s}$. These simulations correctly reproduced all the zones and subzones of the hydraulic jump, which allowed to perform an evaluation of the water jump location (distance $R_{j}$ from the axis of the impinging jet, see Fig. $3)$. Figure 4 illustrates the good predictive capability of the present numerical simulations: the water jump evolution with increasing volume flow rate of water is close to the recent experimental results given in [7].

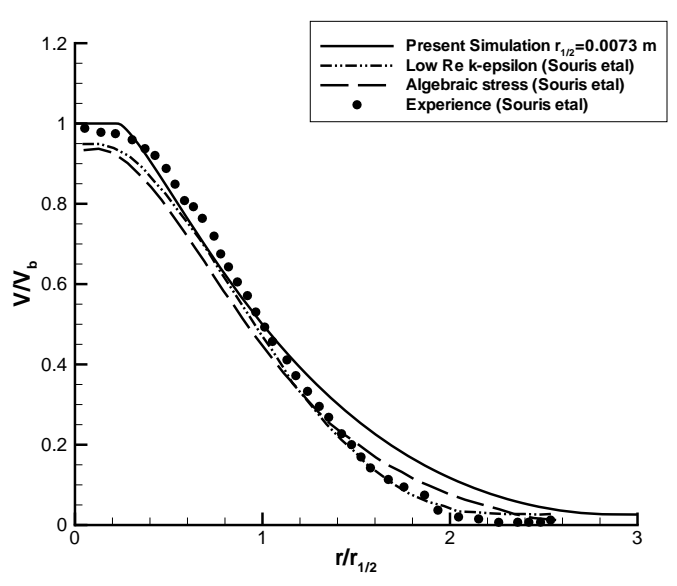

Figure 1: Non-dimensional free-jet velocity profiles for a distance of $H_{p} / D_{n}=4$ away from the impact surface. $r_{1 / 2}$ is the radial distance where $V=V_{b} / 2$ and $V_{b}$ is the fluid velocity at the center line of the jet

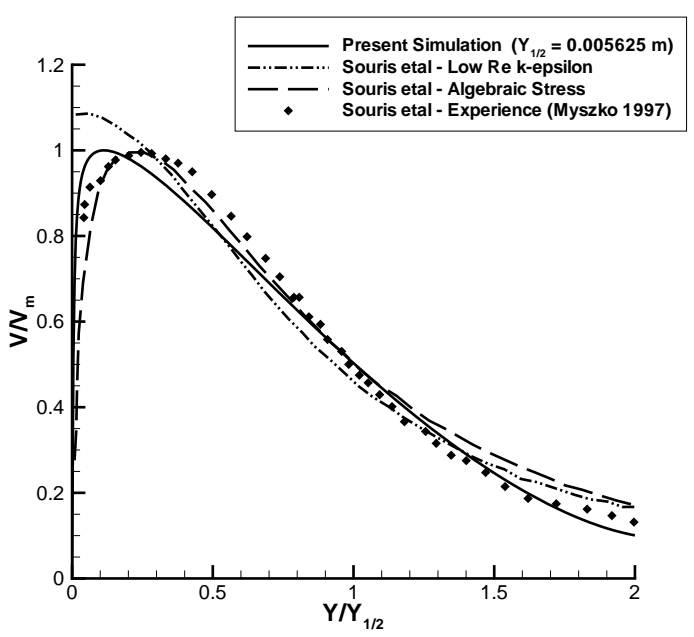

Figure 2: Non-dimensional wall-jet velocity profiles for a distance of $r / D_{n}=3$ away from the jet axis. $Y_{1 / 2}$ is the axial distance where $V=V_{\max } / 2$

It should be stated that the slight overestimation detected in the simulations could be caused by the rather coarse grid used (27000 cells), which was retained to provide accurate results without leading to expensive computations. 


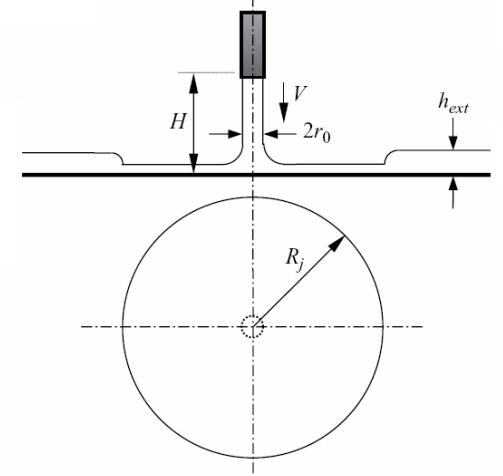

Figure 3: Example of a hydraulic jump in the case of a vertical impinging jet

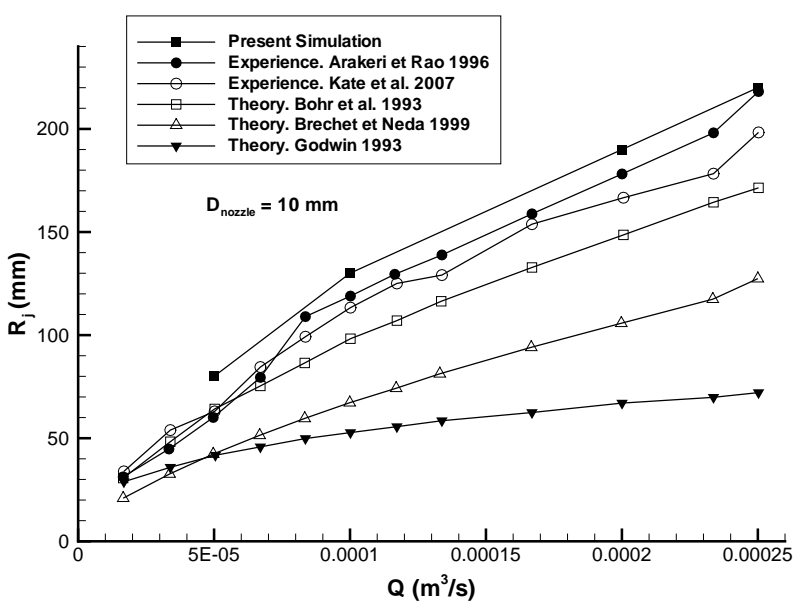

Figure 4: Radius of the circular hydraulic jump $\left(R_{j}\right)$ as a function of the volume flow rate of water

\subsection{Simulation of the particles transport}

Several discrete phase transport models are available in the flow solver used in the study: force balance, Saffman's Lift Force ... In order to assess their performance, the case of a particle-laden jet has been investigated: the experimental work of Shuen et al. [1] at the NASA back in 1983 has been retained as well as the more recent work of Sijercic et al. [5] reproducing semi-analytically and numerically this early experiment.

Three configurations were numerically simulated: a single phase pure air jet (air velocity $U=32.12 \mathrm{~m} / \mathrm{s}$ ) and two sand particles laden air jet with a loading mass ratio of 0.2 and particles of mean diameter 79 and $119 \mu \mathrm{m}$ respectively. The initial air and particles velocity are respectively 26.07 and $24.13 \mathrm{~m} / \mathrm{s}$ for case
2, 29.86 and $24.20 \mathrm{~m} / \mathrm{s}$ for case 3 ; the sand density is $d_{\text {sand }}=2620 \mathrm{Kg} / \mathrm{m}^{3}$. Figures 5 and 6 display respectively the velocity of the air and the particles on the jet centerline for case 2 and compares the numerical results with the data provided by Sijercic et $a l$. The results obtained for case 3 are very similar to those of case 2 and will not be presented here. The jet and particles properties remain close to the experiments, especially in the first part of the free jet zone $(x / D<10)$ which is of interest for the targeted application in this work since, in the context of AWJ machining, the distance between the nozzle and the work piece rarely exceeds $h=2 D$.

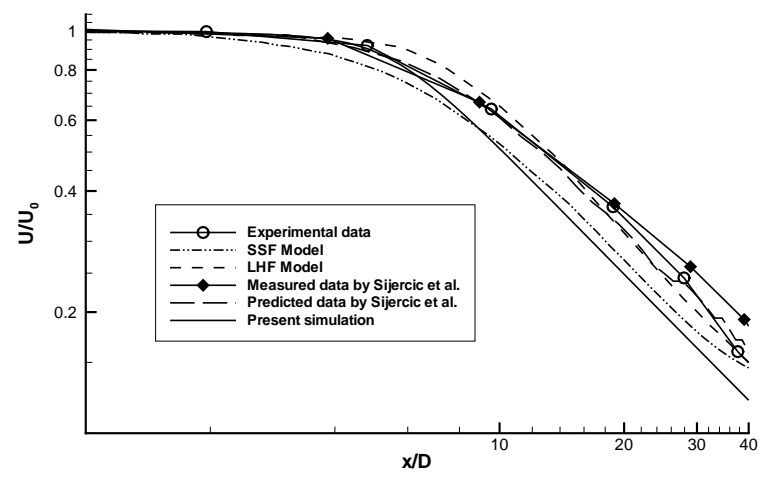

Figure 5: Non-dimensional air velocity along the jet centerline for case 2

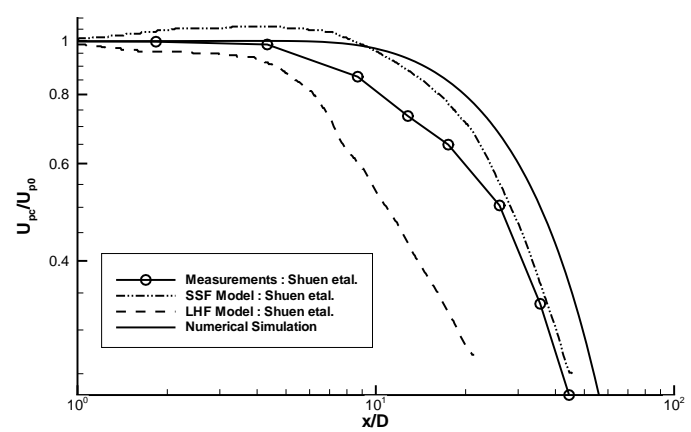

Figure 6: Non-dimensional particle velocity along the jet centerline for case 2

\section{MATERIAL REMOVAL MODEL}

Having validated the suitability of the fluid solver to our conditions of simulation, the next step of our work is to couple the flow simulation of a multiphase, high 
speed, charged jet impinging on a deformable solid with a material removal code. A preliminary test has been performed with a very simple erosion model, implemented as a wall boundary condition in the flow solver. More precisely, the impacted surface undergoes a deformation defined by the following equation:

$$
\delta x_{n, j}=\frac{P\left(y_{j}, t_{n}\right) \cdot \delta t}{K_{\text {crit }}}
$$

where $\delta x_{n, j}$ is the increment at time level $t_{n}$ of the $x$-position of the points on the deformable wall (the $y_{j}$ ordinates are supposed fixed in this highly simplified model), $n$ is the number of time steps, $P$ is the local pressure, $\delta t$ is the time step (in seconds), and $K_{\text {crit }}$ is the Material Damage Factor. This model, coupled with a high velocity turbulent jet $(570 \mathrm{~m} / \mathrm{s})$ and a dynamic mesh model, yields some first qualitative results of a drilling simulation. Figure 7 displays a sequence of pressure contours illustrating the material removal induced by the jet impact. However, the physical meaning of such a simulation has to be considered with caution owing to the obvious model limitations: the deformation is considered to be in the $x$-direction only and the value of the parameter $K_{\text {crit }}$ has been tuned in order to obtain a moderate speed of penetration of the jet in the solid (mainly for ensuring robustness of the dynamic mesh process and enabling this feasibility study but without proper consideration of the physical characteristic times of the process).

\section{CONCLUSIONS}

All the numerical results presented to support the validation of the fluid solver proved quite satisfactory: impacting water jets in still water and air as well as free jets with particles have been successfully computed, thus providing a convincing validation of the multiphase and particle transport models. A study of a complete AWJ flow, including the coupling of the fluid flow simulation with some material removal models, can be undertaken with confidence. Our work is currently focused on the improvement of the material removal model: the deformation in the $y$-direction is being introduced and the value of $K_{c r i t}$ is modified in order to be based on the material properties of the work piece, the cutting speed and other parameters that we intend to determine after some planned experiments with an AWJ machine in the LMSP Laboratory of ENSAM.
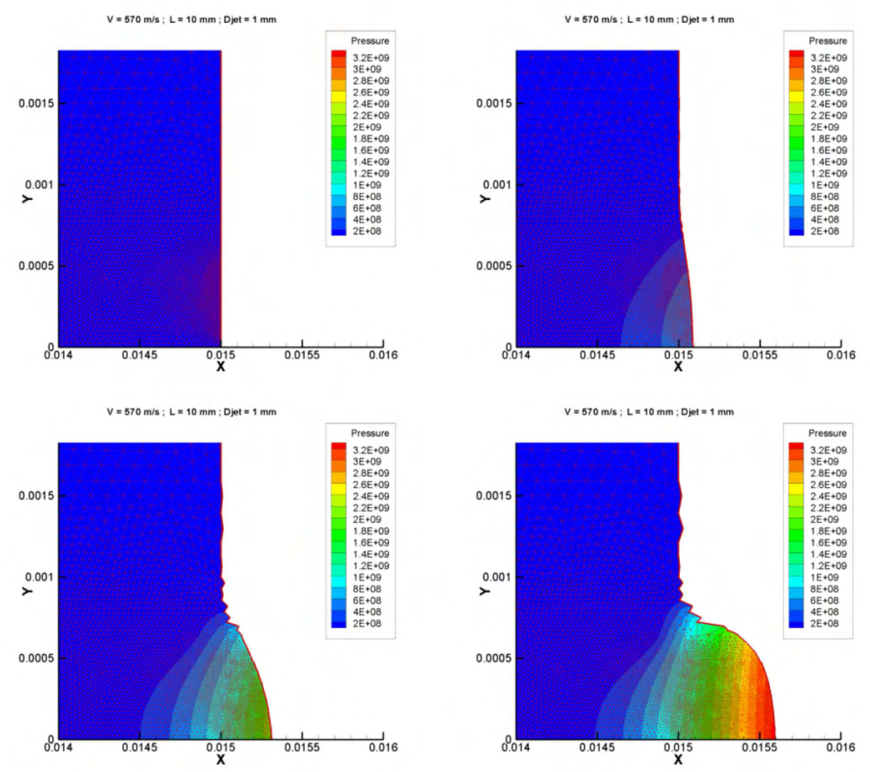

Figure 7: Evolution of the water jet drilling. Evolution of the pressure contours. New cells of the computational domain are generated based on a skewness and size conditions in the dynamic mesh model of the flow solver. Jet velocity $=570$ $\mathrm{m} / \mathrm{s} ;$ Nozzle diameter $=1 \mathrm{~mm} ; h / D=10$

\section{REFERENCES}

[1] Q.F. Zhang et al. J.S. Shuen, A.S.P. Solomon. The structure of particle-laden jets and non-evaporating sprays. NASA, CR-168059, 1983.

[2] F. Xiao K. Yokoi. A numerical study of the transition in the circular hydraulic jump. Physics Letters A, 257(1):153-157, 1999.

[3] F. Xiao K. Yokoi. Mechanism of structure formation in circular hydraulic jumps: numerical studies of strongly deformed free-surface shallow flows. Physica D, 161(1):202219, 2002.

[4] K. Knowles and M. Myszko. Turbulence measurements in radial wall-jets. Experimental Thermal and Fluid Science, 17(1):71-78, 1998.

[5] Z. Stevanovic M. Sijercic, S. Belosevic. Simulation of free turbulent particle-laden jet using reynolds-stress gas turbulence model. Applied Mathematical Modelling, 31(1):10011014, 2007.

[6] M. Founti J. Palyvos N. Souris, H. Liakos and N. Markatos. Study of impinging turbulent jet flows using the isotropic low-reynolds number and the algebraic stress methods. Computational Mechanics, 28(1):381-389, 2001.

[7] S. Chakraborty R. P. Kate, P. K. Das. Hydraulic jumps due to oblique impingement of circular liquid jets on a flat horizontal surface. J. Fluid Mech., 573(1):247-263, 2007. 